\title{
A Review on the Safety and Efficacy of Inhaled Corticosteroids in the Management of Asthma
}

\author{
Qian Ye $\cdot$ Xiao-Ou He $\cdot$ Anthony D'Urzo
}

Received: January 11, 2017 / Published online: April 20, 2017

(C) The Author(s) 2017. This article is an open access publication

\begin{abstract}
Asthma is a chronic inflammatory disease characterized by symptoms of cough, dyspnea, chest tightness, and wheeze. Inhaled corticosteroids (ICS) have been recommended as initial therapy in the treatment of persistent asthma in all guidelines, as they have been shown to reduce morbidity and mortality. However, high-dose regimens and long-term use of ICS may be associated with a variety of side effects, similar to those observed with systemic corticosteroid therapy. These side effects include impaired growth in children, osteoporosis, fractures, glaucoma, cataracts, and skin thinning. The current recommendations on ICS use in asthma management will be reviewed in this article with a view to highlight treatment
\end{abstract}

Enhanced content To view enhanced content for this article go to http://www.medengine.com/Redeem/ B718F0604485CFE5.

Q. Ye

John A. Burns School of Medicine, University of Hawaii at Manoa, Honolulu, HI, USA

Xiao-OuHe

Faculty of Medicine, University of Manitoba,

Winnipeg, MB, Canada

\section{A. D’Urzo ( $\square)$}

Department of Family and Community Medicine, University of Toronto, Toronto, ON, Canada e-mail: tonydurzo@sympatico.ca strategies that strike an optimal balance between safety and efficacy.

Keywords: Add on therapy; Airway inflammation; Asthma; Dose-response; Efficacy; Inhaled corticosteroids; Mechanism of action; Pathophysiology; Safety; Side effects

\section{INTRODUCTION}

Asthma is a chronic inflammatory disease of the airways characterized by varying degrees of bronchoconstriction and airway hyperresponsiveness leading to classic symptoms of airway obstruction that is often reversible.

The first asthma management guidelines were published in the mid 1980s in Australia and New Zealand. Since then, the Global Initiative for Asthma (GINA), the National Asthma Education and Prevention Program (NAEPP), the Canadian Thoracic Society (CTS), and the British Thoracic Society guidelines have become available for implementation and dissemination [1].

Current treatment of asthma is aimed at reducing the severity of symptoms day-to-day and minimizing future risks including severe exacerbations, hospitalizations, and death. Inhaled corticosteroids (ICS) are the mainstay of controller therapy and are the standard of care in long-term asthma treatment. ICS has been 
shown to decrease severe exacerbations [2], hospitalization [3], and death [4]. The therapeutic benefit from ICS is achieved at low doses yielding a relatively high benefit-to-risk ratio. However, fear of unwanted local and systemic side effects remain a concern in patients using ICS, especially with high-dose regimens and long-term use [5].

The risks associated with systemic exposure to ICS have been extensively studied, and include suppression of hypothalamic-pituitary-adrenal (HPA) axis, growth retardation in children, reduction in bone mineral density and osteoporosis, fractures, cataract formation, glaucoma, skin thinning, and easy bruising [6]. The objectives of this review article are to review current strategies on the role, safety, and efficacy of ICS usage in asthma control.

This article is based on previously conducted studies and does not involve any new studies of human or animal subjects performed by any of the authors.

\section{PATHOPHYSIOLOGY OF ASTHMA}

Asthma is a chronic multifactorial airway disorder that involves a complex interplay of chronic inflammation, bronchial hyperresponsiveness, and airflow obstruction. The interaction of these factors determines the clinical manifestation and severity of asthma and the response to treatment [7].

\section{Airway Inflammation}

\section{Acute Inflammatory Response}

In susceptible individuals, the inhaled allergen is trapped in the mucus lining of the airway and taken up by antigen-presenting cells, most notably dendritic cells. After antigen take up, the dendritic cells present the antigen to naive CD4+ T cells. This cell-cell interaction determines whether the naive CD4+ T cell will differentiate into T-helper type 1 (Th1) or T-helper type 2 (Th2) phenotype. In an atopic asthmatic, a predominate $\mathrm{Th} 2$ response is seen, favoring the development of allergic inflammation [8]. B cells, in the presence of interleukin (IL)- 4 and IL-13, produce antigen-specific IgE that binds to high-affinity IgE receptors on mast cells causing degranulation and release of synthesized mediators that result in bronchoconstriction, airway edema, and local tissue damage [8].

\section{Late Inflammatory Response}

Chemo-attractants released from mast cells recruit eosinophils, basophils, neutrophils, and lymphocytes, which contribute to the latephase inflammatory response. The eosinophils are the most important and abundant inflammatory cells associated with the late-phase response. IL-5 secreted by Th2 cells enhances eosinophil growth, maturation, and migration, leading to release of toxic granular proteins and additional cytokines and chemokines [9]. Eosinophil activity results in local tissue damage, mucus hypersecretion, increased vascular permeability, smooth muscle contraction, and a persistent inflammatory response, whereby other cell types are recruited to the site of inflammation to perpetuate the reaction [8].

\section{Airway Hyperresponsiveness}

Airway hyperresponsiveness is an exaggerated bronchoconstrictor response to stimuli. Factors such as inflammation, neurological dysregulation, and structural changes all influence airway hyperresponsiveness, but inflammation appears to be a major factor in determining the degree of airway hyperresponsiveness. It is well known that ICS therapy improves airway hyper responsiveness in asthmatics [7].

\section{Bronchoconstriction}

Airflow limitation is the dominant physiological event leading to clinical symptoms in asthma. Allergen-induced bronchoconstriction results from IgE-dependent mast cell degranulation and release of mediators such as histamine, tryptase, leukotrienes, and prostaglandins [10]. Aspirin and other nonsteroidal anti-inflammatory drugs cause mediator release and bronchoconstriction in some patients via a non-IgE-dependent response [11]. Other stimuli such as exercise, cold air, and irritants can also cause acute airflow obstruction 
in certain patients, although the exact mechanisms are not well understood [7].

\section{Airway Remodeling}

Chronic airway inflammation may lead to airway remodeling, which involves activation of structural cells that cause permanent changes in the airway and result in increased airflow obstruction and airway responsiveness and render the patient less responsive to therapy [12]. Features of airway remodeling include basement membrane thickening, subepithelial fibrosis, airway smooth muscle hypertrophy and hyperplasia, blood vessel proliferation and dilation, and mucous gland hyperplasia and hypersecretion [7]. On a molecular level, airway remodeling occurs from a complex interaction between epithelial, dendritic, eosinophils, Tlymphocytes, mast cells, and neutrophils [13]. These permanent structural changes result in irreversible airflow limitation, persistent disease, progressive loss of lung function, and limited therapeutic response [7].

\section{INHALED CORTICOSTEROID MECHANISM OF ACTION}

ICS molecules diffuse through the cell membrane of respiratory epithelial cells and other cells in the airway and bind to glucocorticoid receptors (GR) in the cytoplasm. The steroid-receptor complex then translocates into the nucleus and binds to glucocorticoid-response elements (GRE) in the promoter region of steroid-sensitive genes, which may encode anti-inflammatory proteins [14]. The overall effect is suppression of activated inflammatory genes and increased transcription of anti-inflammatory genes. Through suppression of airway inflammation, ICS reduce airway hyperresponsiveness and control asthma symptoms [7]. Suppression of gene transcription accounts for many of the side effects of corticosteroids. For instance, corticosteroids inhibit the expression of osteocalcin, which is involved in bone synthesis [15]. Inhaled $\beta_{2}$-agonists and ICS are often used together in treating asthma. It is believed that ICS up-regulate membrane $\beta_{2}$ receptors [16] while $\beta_{2}$-agonists may indirectly influence the anti-inflammatory effects of ICS [17].

Smoking asthmatics and patients with severe asthma appear to be relatively corticosteroid-resistant, unlike patients with chronic obstructive pulmonary disease (COPD) where steroid responsiveness is generally poor [14]. In these patient populations, there is a reduction in histone deacetylase-2 (HDAC2) activity and expression, which prevents corticosteroids from switching off activated inflammatory genes [18-20]. Activated GR normally recruits HDAC2, which reduces histone acetylation induced by proinflammatory transcription factors such as nuclear factor kappa B (NFkB), thereby switching off activated inflammatory genes. Oxidative stress generated from cigarette smoke and intense inflammation in severe asthma and COPD impairs the activity of HDAC2 and reduces the anti-inflammatory effect of corticosteroids [14].

\section{FACTORS INFLUENCING THE EFFICACY AND SAFETY OF ICS}

\section{Fate of ICS}

After inhalation, the majority of drug particles deposit directly in the oropharynx, central airways, or in alveoli, depending on the size of particles as well as the delivery devise used. Approximately $10-60 \%$ of the inhaled dose is deposited in the lungs [21-23]. Direct deposition of the ICS in the lungs allows targeted delivery and thus targeted therapeutic actions. The drug molecules in the lungs can enter the systemic circulation via pulmonary vasculature, leading to potential systemic side effects. The fraction of ICS (40-90\%) deposited in the oropharynx can cause local oropharyngeal side effects. Patients are advised to rinse their mouths to remove these deposited particles, but the fraction that persists after rinsing may be swallowed and absorbed by the gastrointestinal tract. The liver inactivates a fraction of the absorbed drug in first-pass metabolism. The remaining drug that eventually reaches the 
systemic circulation can potentially cause systemic side effects [21].

\section{Pharmacokinetics}

The goal of ICS therapy is to achieve high topical anti-inflammatory effect locally in the airway mucosa with minimal to no unwanted local and systemic effects [24]. The fraction of ICS that reaches the systemic circulation is absorbed from the airway, alveolar surface, and the gut after the oropharyngeal deposits are swallowed [14]. The systemic bioavailability depends on gastrointestinal bioavailability and the amount of ICS that enters the systemic circulation via lungs. Ideal features of an ICS that confer a high therapeutic index include a high affinity for and potency at the GR, high level of serum protein binding for the systemically absorbed fraction, prolonged retention in the lung, minimal to no oral bioavailability, and rapid and complete systemic inactivation (i.e., high first-pass hepatic inactivation) [25].

In general, the higher the GR binding affinity, the more potent the ICS is. However, high receptor binding affinity does not necessarily translate into increased clinical efficacy due to other pharmacokinetic and pharmacodynamic factors involved [5]. The available ICS are listed in Table 1 (adapted from [26, 27]) in order of potency. Lipophilicity (helps prolong pulmonary residency time), plasma protein binding and tissue distribution all follow the same trend. Budesonide and fluticasone propionate (FP) have high first-pass metabolism and low oral bioavailability that confer them high therapeutic indexes. The two newest ICS, mometasone furoate and ciclesonide (CIC) also have very low oral bioavailability, similar to that of FP $[28,29]$. Beclomethasone dipropionate (BDP) and CIC are converted to their active metabolites, beclomethasone 17-monopropionate (BMP) and desisobutyryl ciclesonide (des-CIC), respectively, in the airway [27]. This lung-specific on-site activation provides targeted anti-inflammatory action within the lung and reduces risk of systemic side effects. Budesonide and CIC have been shown to undergo reversible fatty acid esterification in the airways, which significantly prolongs pulmonary residence time by providing a local depot in the lung for slow release of the active compound [30-32].

CIC is a new-generation ICS designed as a pro-soft drug to mitigate the side effects of ICS. It has many favorable pharmacokinetic properties such as low oral bioavailability, high plasma protein binding, rapid systemic clearance, high pulmonary deposition and distribution, and long pulmonary residence time. These advantageous properties reduce the occurrence of local and systemic side effects. Recent efficacy and safety studies support that CIC is effective in improving the lung functions with very low oropharyngeal and systemic side effects in comparison to other ICS [33]. In addition, its once-daily administration and high safety profile may improve patient compliance with ICS therapy [5].

Interestingly, there appears to be significant variability in response to ICS. Szefler et al. examined the benefit-to-risk ratio of BDP-metered-dosed inhaler (MDI) and FP-MDI in a 24-week, parallel, open-label, multicenter trial [34]. Significant variability in response to ICS for two important measures of efficacy-forced expiratory volume in 1 second $\left(\mathrm{FEV}_{1}\right)$ and methacholine PC20 was reported. This variability in response is consistent with observations reported in many other studies.

\section{Delivery Devices}

Delivery devices and patient technique are primary determinants of the dose delivered to the lungs [7, 38]. Four delivery systems are available for ICS: MDI, dry-powder inhaler (DPI), Respimat ${ }^{\circledR}$ Soft Mist ${ }^{\mathrm{TM}}$ Inhaler (SMI), and a nebulizer $[25,39]$. The particle size generated by each system will affect drug deposition and thus the potential dose delivered to the lungs. MDI formulations are propelled by either hydrofluoroalkane (HFA) or chlorofluorocarbon, which has been phased out. MDI emit particles of various size, some of which are outside the respirable range. A valved holding chamber (spacer) increases the percentage of inhaled particles that are within the respirable range 


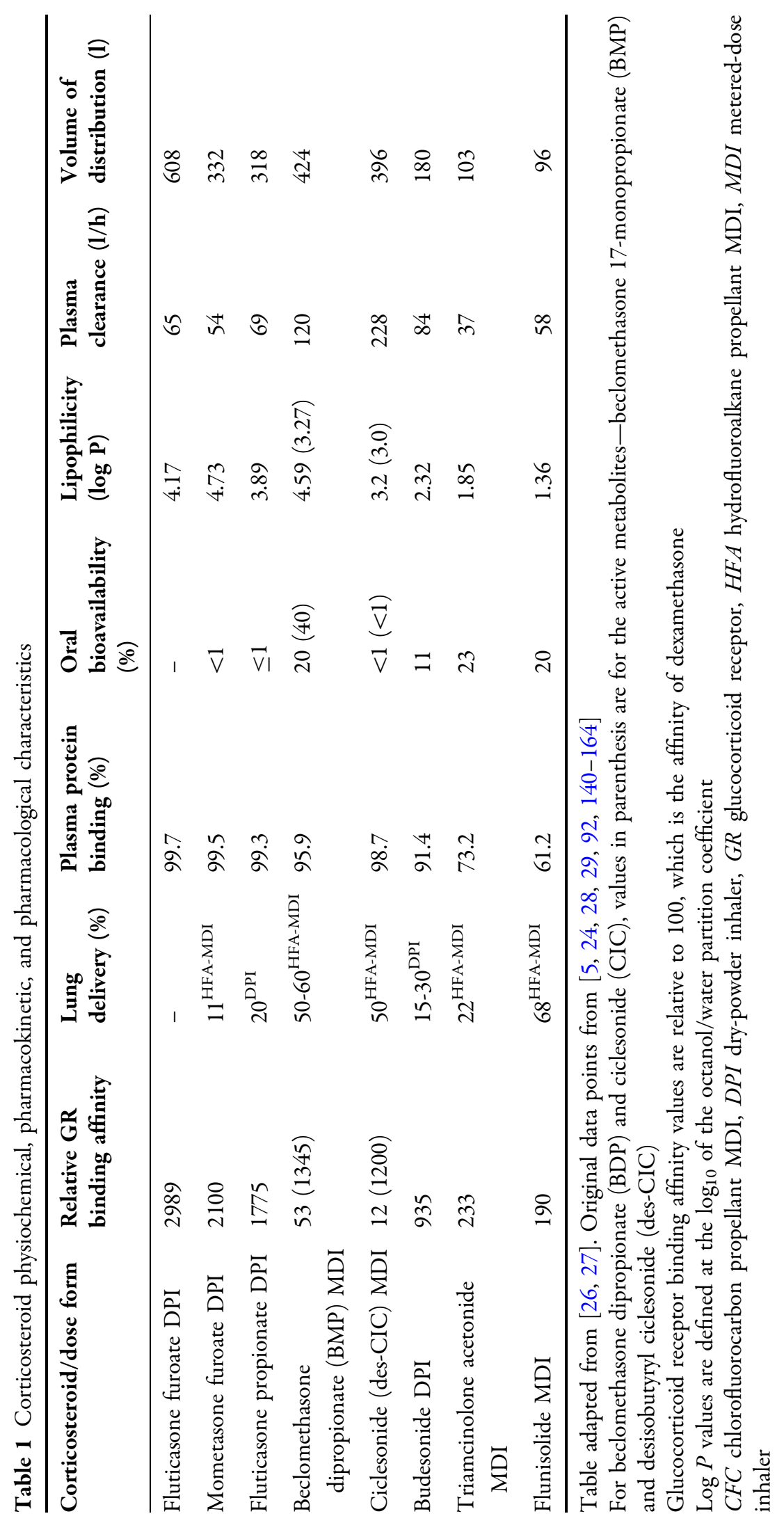


and captures larger particles that would otherwise be deposited in the oropharynx [25].

SMI were introduced in 2007 to solve some disadvantages associated with pressurized MDI (pMDI) and DPI, such as deposition of drug in the oropharynx [40]. The design concept is similar to pMDI. However, SMI use a spring-powered delivery system rather than a pressurized container to generate a low velocity vapor with a high fine-particle fraction. Compared to aerosols from pMDI and DPI, lung deposition with SMI is up to 50\% higher and oropharyngeal deposition is lower [41].

\section{Dosing Frequency}

Few studies have compared once-daily ICS dosing with twice or more frequent daily dosing in patients with asthma in real-world settings. Wells et al. showed that once-daily dosing was associated with significantly higher adherence to ICS therapy [35]. Patients with once-daily dosing were more than three times as likely to achieve $>75 \%$ adherence, a threshold previously associated with therapeutic benefit, when compared to multiple daily dosing $[35,36]$. In addition, the once-daily regimen did not appear to compromise the clinical efficacy of asthma controller therapy.

A Cochrane review of several randomized controlled trials that compared the efficacy and safety of intermittent versus daily ICS in adults and children with persistent asthma concluded that intermittent and daily ICS were similarly effective in the use of rescue oral corticosteroids and the rate of severe adverse health events, although the quality of evidence is low [37]. Daily ICS was superior to intermittent ICS in terms of lung function, airway inflammation, asthma control, and reliever use.

\section{DOSE-RESPONSE RELATIONSHIP}

ICS demonstrate a dose-response relationship from low to medium doses with no significant additional therapeutic benefit in the high-dose range in patients with mild-to-moderate persistent asthma [42]. The first report published in the 1990 s by Dahl et al. demonstrated this dose-dependency in FP via parameters such as morning peak expiratory flow (PEF), $\mathrm{FEV}_{1}$, percentage of symptom-free days, and rescue bronchodilator use to assess clinical efficacy [43]. Similar results have been reported for other ICS, such as BDP [44], triamcinolone acetonide [45], and mometasone furoate [46]. The therapeutic dose range for all clinical outcome measures in adults is $100-1000 \mu \mathrm{g} /$ day of BMP or budesonide [7, 47]. However, the dose-response effect of ICS may depend on the parameters measured. A meta-analysis conducted by Currie et al. using bronchial hyperresponsiveness (BHR) as a clinical endpoint demonstrated a dose-response effect even at high doses [48]. BHR is a reliable surrogate marker of underlying airway inflammation $[49,50]$ and may be more sensitive than traditional outcome measures such as symptoms or lung-function tests in the assessment of the effects of ICS.

ICS also exhibit a dose-response relationship for the systemic side effects, as evidenced by meta-analysis studies on the major side effects of ICS [51]. In addition, this dose-dependency is evident throughout the entire dose range and the undesirable effects are most prominent in patients receiving high doses of ICS. At higher doses, the curve for therapeutic efficacy becomes relatively flat and the dose-response curve for systemic side effects remains steep (see Fig. 1 [52]). An increase in the dose of any ICS decreases the therapeutic index (the ratio of the therapeutic effect to systemic adverse effect) [53]. The studies on dose-response relationships in clinical efficacy and systemic adverse effects provide robust evidence on why ICS should be titrated to the lowest effective dose once asthma symptoms are under control.

Nevertheless, most guidelines still recommend the use of high-dose ICS for the treatment of patients with severe persistent asthma. This recommendation is based, in part, on the results of the Formoterol and Corticosteroids Establishing Therapy (FACET) trial described below [51, 54].

\section{STEPWISE DOSE REDUCTION OF ICS}

Current guidelines (i.e., NAEPP and GINA) suggest that patients with good asthma control 


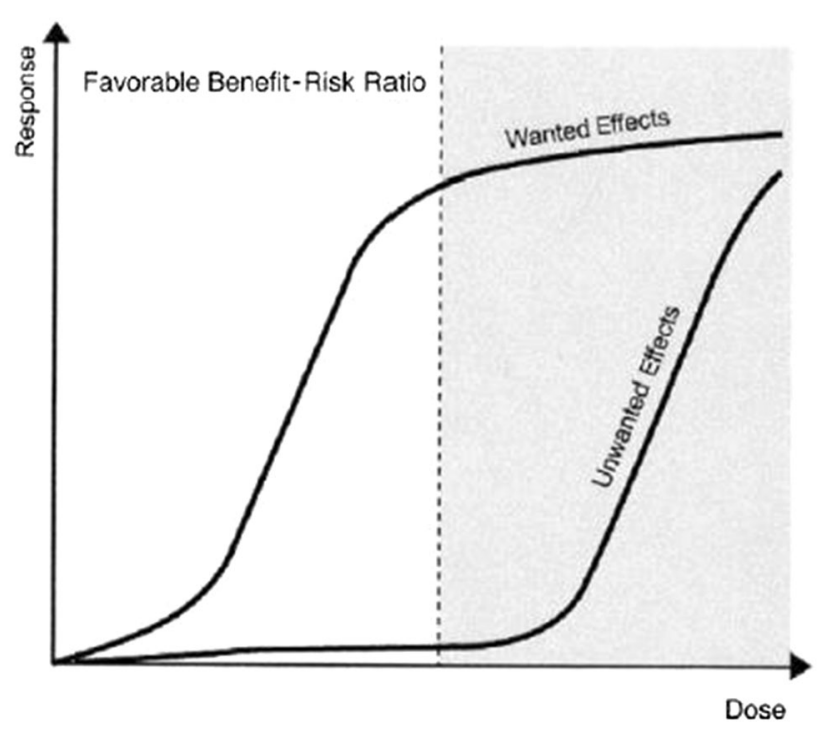

Fig. 1 Schematic dose-response curves showing the wanted and unwanted effects (i.e., systemic side effects) of an inhaled corticosteroid (ICS). As the dose increases,

and low risk of future exacerbations should be considered for step-down therapy to the lowest effective dose [55]. GINA recommends stepping down treatment once good asthma control has been achieved and maintained for 3 months [56]. Guidelines suggest reducing the ICS dose by $25-50 \%$ at 2 to 3 -month intervals for stepping down, which is supported by systematic review and meta-analysis findings $[7,57]$. These step-down recommendations are supported by low levels of evidence and limited by the small number of studies available.

Analysis of randomized controlled trial (RCT) studies that examined step-down of asthma medications suggested that each of the methods of stepping down from ICS to reduced ICS dose [58-61], scheduled ICS to on demand ICS $[57,62]$, or ICS to leukotriene receptor antagonist (LTRA) [63] may be safe options for many patients with stable asthma. However, each of these step-down strategies likely confers an increased risk of having an exacerbation or loss of asthma control compared with continuing the current asthma regimen. Physicians should discuss these risks with their patients to facilitate informed decision-making. There remain a lot of gaps in our understanding of asthma step-down therapy, risks, and benefits [55]. Further research studies are required to the therapeutic index of any ICS decreases. Reproduced with permission from Pedersen and O’Byrne [52]

develop a comprehensive evidence-based stepdown algorithm that includes relevant longterm asthma control measures as primary outcomes.

Several studies have reported possible predictors for failing step-down attempts. These factors can be categorized as clinical, demographic, physiologic, and biologic. Clinical and demographic characteristics associated with failure include age $>40[64,65]$, disease duration $>5$ years [66], length of time with no clinical symptoms before ICS reduction [67], and time of year [68]. Physiologic markers include bronchial hyperresponsiveness [65, 67] and the level of $\mathrm{FEV}_{1}$ [67]. Biologic markers such as sputum eosinophils $[65,66,69]$, fractional excretion of nitric oxide $\left(\mathrm{F}_{\mathrm{ENO}}\right)[67,69]$, serum eotaxin (CCL-11) [70], serum eosinophil count [66], and serum eosinophil cationic protein [71] can be used to guide step-down therapy and to monitor the success of ICS withdrawal. Sputum eosinophils may have a good predictive value for failure of ICS reduction during back titration as it has been shown to be predictive in three studies, including serial measurements [55]. However, this laboratory test is not widely performed and may not be easily implemented. On the other hand, $\mathrm{F}_{\mathrm{ENO}}$ level has been shown to correlate well with sputum eosinophilia 
$[72,73]$. Studies have shown that the $\mathrm{F}_{\mathrm{ENO}}$ level responds the earliest to treatment and withdrawal of ICS [74]. Monitoring the $\mathrm{F}_{\mathrm{ENO}}$ level in patients with asthma may enable ICS reduction without compromising asthma control [75]. Future studies can combine these predictors to derive failure indices for stepping down asthma medications, recognizing that ICS reduction strategies may differ among individuals with controlled asthma of varying severity.

\section{COMBINING ICS WITH LONG-ACTING $\mathrm{B}_{2}$-ADRENERGIC RECEPTOR AGONIST}

\section{Safety and Efficacy}

In patients who are not controlled on low- or medium-dose ICS, addition of an inhaled long-acting $\beta_{2}$-adrenergic receptor agonist (LABA) such as salmeterol or formoterol has been shown to be more efficacious than increasing the dose of ICS. A study by Greening et al. [76] compared PEF as a primary variable between a group administered $400 \mu \mathrm{g} /$ day BDP plus $100 \mu \mathrm{g} /$ day salmeterol and a group administered $1000 \mu \mathrm{g} /$ day BDP alone for 6 months in mild-to-moderate asthma. The add-on therapy with salmeterol resulted in significantly more favorable outcomes in terms of PEF change from baseline, the need for rescue medication, and the number of symptom-free days [76, 77]. Recent multicenter, randomized, double-blind studies showed that treatment with budesonide/formoterol and fluticasone/salmeterol were associated with a lower risk of asthma exacerbations than budesonide alone and fluticasone alone groups respectively [78, 79]. There have been concerns about the safety of LABA use in patients with asthma [80, 81], but patients who received the ICS/LABA combination preparations did not have a significantly higher risk of serious asthma-related events than did those who received ICS alone. Most current guidelines recommend adding a LABA to low- or medium-dose ICS when escalating asthma treatment. The GOAL trial by Bateman et al. [82] showed that guideline-defined control of asthma can be achieved in the majority of patients with uncontrolled asthma with combination salmeterol/fluticasone treatment more rapidly and at a lower dose of ICS than fluticasone alone.

Nevertheless, most guidelines still recommend the use of high-dose ICS for the treatment of patients with severe persistent asthma. The FACET trial showed that high-dose ICS treatment reduced the frequency of severe acute exacerbations of asthma in patients with severe asthma independent of the addition of formoterol [54]. The effect of increasing the dose of budesonide was significantly more pronounced than the effect of adding formoterol only in patients with severe exacerbations. This study provided the rationale for increasing the maintenance dose of ICS for patients with repeated severe exacerbations of asthma. In patients with mild disease, the OPTIMA trial revealed that addition of formoterol to low-dose budesonide resulted in significant reductions in exacerbations but not when formoterol was added to ICS in previously steroid-naive patients [83].

Finally, multiple double-blind, randomized trials have demonstrated that when budesonide/formoterol is used as a single inhaler for both maintenance and reliever therapy (often referred to as SMART therapy) it gives a better control of asthma compared to using short- or long-acting $\beta_{2}$-agonist as a rescue therapy with either the same dose combination inhaler [84] or an ICS alone as maintenance treatment [84-86].

\section{Step-off LABA}

ICS/LABA combination formulations, such as fluticasone/salmeterol and budesonide/formoterol, have helped achieve good asthma control in a large proportion of patients [87]. However, because of LABA's potential risk of increasing severe exacerbation of asthma symptoms and death, the American Food and Drug Administration recommends withdrawal of LABA once asthma is controlled by ICS/LABA combination therapy. Well-controlled asthmatic patients should be maintained on an 
asthma controller medication (i.e., ICS) without LABA [88]. Mori et al. compared the efficacy between two step-down strategies: to reduce ICS/LABA dose or to withdraw LABA continuing ICS in well-controlled asthmatics. Their prospective multicenter randomized controlled study suggested that these two step-down strategies are equally acceptable in well-controlled asthmatics treated with medium-dose of budesonide/formoterol. The incidence of asthma exacerbations was not significantly different between the two study groups. There was also no significant difference in Quality of Life score and $\mathrm{F}_{\mathrm{ENO}}$ level between 0 week and 12 week in both groups, although withdrawal of LABA may potentially deteriorate $\mathrm{FEV}_{1}$ [89]. On the other hand, a recent meta-analysis by Bozek et al. concluded that the LABA step-off approach was not favorable as it increased asthma-associated impairment [90].

\section{SIDE EFFECTS}

\section{Local Side Effects}

The main local side effects are oral candidiasis, cough at time of inhalation, hoarse voice, and dysphonia [91]. The cough is due to a local irritant effect and may be resolved by using a spacer chamber or slowing the rate of inhalation. Oral candidiasis is dose-related and occurs in $<5 \%$ of patients. It can be prevented simply by rinsing the mouth with water after ICS use. Dysphonia and hoarseness are also dose-related, and may be due to steroid myopathy of the laryngeal muscles [91]. Both were found to be worse with DPI delivery devices than with MDI.

\section{Systemic Side Effects}

Systemic side effects of ICS depend on several factors: the dose delivered, delivery device used, site of delivery, and individual differences in response to the corticosteroid [14]. The systemic effect of an ICS depends on the amount of the drug absorbed into the systemic circulation. Absorption can occur through the gastrointestinal tract after the fraction of ICS deposited in the oropharynx is swallowed or from the lungs after inhaling the drug. The use of a spacer and mouth washing help reduce systemic absorption. A spacer reduces oropharyngeal deposition and increases delivery to the lungs. More efficient delivery to the lungs can increase systemic absorption, but this is offset by a reduction in the dose required for optimal control of airway inflammation [14]. In patients with severe asthma, studies have suggested a reduced propensity for systemic side effects, presumably due to decreased lung bioavailability of ICS secondary to reduced airway diameter $[92,93]$.

\section{Hypothalamic-Pituitary-Adrenal (HPA) Axis Suppression}

The most serious adverse effect of ICS is dose-related suppression of the HPA axis. The extent of suppression is dependent on the dose, duration, and timing of ICS administration [94-98]. In adults, HPA suppression appears to occur at doses above $800 \mu \mathrm{g} /$ day BDP equivalent [99]. The most serious side effect of long-term ICS use is adrenal crisis after complete suppression of HPA-axis $[97,98]$. Although rare, adrenal crisis may be a real concern for patients receiving unsafe doses, especially the pediatric patients. Basal cortisol level is often used as a marker of adrenal suppression. It is clear that even low-to-medium ICS doses can disturb basal cortisol secretion in children and adults [98, 100-103], but whether this disturbance has any clinical significance remains unclear [5].

\section{Growth Suppression in Children}

Asthma itself has been associated with delayed onset of puberty and deceleration of growth velocity, with the effects more prominent in severe disease. The effect of asthma on growth pattern and courses of oral corticosteroids make it difficult to isolate the effects of ICS use on growth [14]. Short- and long-term studies suggest that patients who are treated with ICS may experience transient non-progressive decreases in growth velocity, but ultimately attain normal adult height [104-106]. The 2007 NAEPP Expert Panel Report 3 asserts that ICS at the recommended doses are unlikely to cause long-term, 
clinically significant, or irreversible effects on linear growth [7]. Two major long-term studies that support the assertion are the Childhood Asthma Management Program (CAMP) study [104] and the Prevention of Early Asthma in Kids study [107].

A recent meta-analysis of 16 RCT showed that ICS use for $>12$ months in children significantly reduced growth velocity at 1 -year follow-up [108]. Final adult height showed a mean reduction of $-1.20 \mathrm{~cm}$ with budesonide versus placebo in a high-quality RCT by Kelly et al. [109]. A larger daily dose was associated with a lower adult height. This particular study measured adult height in 943 of 1041 (90.6\%) participants in the CAMP study where participants starting at the age of 5-13 years were randomized to receive budesonide $(400 \mu \mathrm{g})$, nedocromil $(16 \mathrm{mg})$, or placebo daily for $4-6$ years. It demonstrated that the initial decrease in attained height associated with ICS use in prepubertal children did persist as a reduction in adult height, although this decrease was neither progressive nor cumulative [109].

\section{Bone Mineral Density, Fractures, and Osteoporosis}

The effects of oral corticosteroids on osteoporosis and the risk of fracture are well established. The long-term effect of ICS on the risk of fracture still needs to be elucidated. Bone densitometry has often been used to assess the effect of ICS on bone mass. However, results may be confounded by the fact that many patients with asthma are also taking intermittent courses of oral corticosteroids [14].

Studies in growing children with asthma suggest that ICS therapy at recommended doses is not associated with a reduction in bone mineral density (BMD) in children [104, 110, 111]. Furthermore, a case-control analysis by Schlienger et al. concluded that exposure to ICS does not increase fracture risk in children and adolescents compared to nonexposed individuals [112].

On the other hand, studies that investigated the impact of ICS on BMD in adult patients with asthma have yielded conflicting results [113]. Some studies have found significant BMD changes in asthmatic patients who received ICS therapy [114-118], while other studies showed no association between ICS treatment and BMD changes [119-122]. A Cochrane review [122] concluded that there is no evidence of an effect of ICS at conventional doses given for 2-3 years on BMD or vertebral fracture. Long-term prospective studies of conventional and high doses of ICS are needed. A recent case-control study suggests that BMD reduction in ICS users with asthma may be dependent on age with the younger patients ( $<50$ years old) being at greater risk of BMD loss [113]. Collectively, the evidence indicates that long-term ICS use affects BMD and risk of fracture in a dose-dependent manner that appears significant at high doses.

\section{Infections and Pneumonia}

With the exceptions of a few case reports on fungal infections, there have been no reports of opportunistic pulmonary infections [123] or increased frequency of infections following prolonged ICS use, even in high doses [14]. In addition, Bahceciler et al. showed that longterm inhaled budesonide therapy is safe for tuberculin-positive children with asthma [124]. However, a meta-analysis by Singh and Loke $[125,126]$ (which is an update of an earlier analysis by the same authors) and several recent case-control studies [127-129] have demonstrated a significantly increased risk of serious pneumonia in COPD [127, 128] or asthmatic patients [129] on ICS therapy. The number needed to harm for pneumonia associated with ICS was estimated to be 60 per year [126]. A dose-response relationship was present with higher ICS doses, conferring greater associated risk of pneumonia [129]. The magnitude of risk for pneumonia was also greater with fluticasone than that seen with budesonide [127-129].

\section{Cataract and Glaucoma}

Although long-term treatment with oral corticosteroids increases the risk of posterior subcapsular cataracts, studies that looked at the risk of cataract formation with ICS use have shown conflicting results. The CAMP Research Group studied the development of posterior subcapsular cataracts in 311 children treated long term with budesonide; only one 
child developed cataract by the end of the 6-year study period [104]. A meta-analysis by Weatherall et al. demonstrated an approximately $25 \%$ elevation in the risk of cataract for each $1000 \mu \mathrm{g} /$ day increase in dose of beclomethasone equivalents [130]. The link between ICS and glaucoma is weaker. Garbe et al. concluded that ICS therapy was not associated with an increased risk of open-angle glaucoma or ocular hypertension [131]. Other studies also showed similar results [132]. Similarly, a recent prospective study showed that inhaled budesonide as much as $800 \mu \mathrm{g} /$ day for a short period of time and long-term use of $200-400 \mu \mathrm{g} /$ day did not cause lens opacities or clinically important increases in intraocular pressure in children with asthma [133]. Collectively, long-term ICS therapy of higher doses may be associated with a higher risk of cataract formation, but the risk of glaucoma is likely very small.

\section{Skin Thinning and Bruising}

Skin bruising and thinning have been documented as side effects of ICS use [134-136], especially in patients receiving high-dose ICS [134]. There is a greater risk of easy bruising in elderly patients [135-139] and in women [135].

\section{CONCLUSIONS}

The potent anti-inflammatory properties of ICS make them the ideal first choice for controller therapy in asthmatic patients with persistent symptoms. ICS appear to have a positive impact on lung function, quality of life, airway hyper responsiveness, and exacerbation rates. Addition of other agents to ICS is linked to improved asthma outcomes, including a reduction in severe exacerbations. Clinicians are encouraged to pursue a clinical management strategy that focuses on achieving current control and reducing future risk using the lowest effective dose of controller therapy, recognizing that all ICS have similar efficacy in the clinical setting. Since the risk-benefit features of ICS are favorable, these agents should be introduced early across all age groups.

\section{ACKNOWLEDGEMENTS}

No funding or sponsorship was received for this study or publication of this article. No medical writing or editorial assistance was received during the writing of this manuscript. All named authors meet the International Committee of Medical Journal Editors (ICMJE) criteria for authorship for this manuscript, take responsibility for the integrity of the work as a whole, and have given final approval for the version to be published.

Disclosures. Qian Ye, Dr. Xiao-Ou He and Dr. Anthony D'Urzo have nothing to disclose.

Compliance with Ethics Guidelines. This article is based on previously conducted studies and does not involve any new studies of human or animal subjects performed by any of the authors.

Data Availability. Data sharing is not applicable to this article, as no datasets were generated or analyzed during the current study.

Open Access. This article is distributed under the terms of the Creative Commons Attribution-NonCommercial 4.0 International License (http://creativecommons.org/licenses/ by-nc/4.0/), which permits any noncommercial use, distribution, and reproduction in any medium, provided you give appropriate credit to the original author(s) and the source, provide a link to the Creative Commons license, and indicate if changes were made.

\section{REFERENCES}

1. Myers TR. Guidelines for asthma management: a review and comparison of 5 current guidelines. Respir Care. 2008;53(6):751-67.

2. Ernst P, Spitzer WO, Suissa S, et al. Risk of fatal and near-fatal asthma in relation to inhaled corticosteroid use. JAMA. 1992;268:3462-4.

3. Donahue JG, Weiss ST, Livingston JM, Goetsch MA, Greineder DK, Platt R. Inhaled steroids and the risk 
of hospitalization for asthma. JAMA. 1997;277:887-91.

4. Suissa S, Ernst P, Benayoun S, Baltzan M, Cai B. Low-dose inhaled corticosteroids and the prevention of death from asthma. $N$ Eng J Med. 2000;343(5):332-6.

5. Rossi GA, Cerasoli F, Cazzola M. Safety of inhaled corticosteroids: room for improvement. Pulm Pharmacol Ther. 2007;20:23-5.

6. Dahl R. Systemic side effects of inhaled corticosteroids in patients with asthma. Respir Med. 2006;100(8):1307-17.

7. Expert panel report 3: guidelines for the diagnosis and management of asthma. Bethesda (MD): National Institutes of Health, National Asthma Education and Prevention Program; 2007. Publication No. 08-4051. http://www.nhlbi.nih.gov/ health-pro/guidelines/current/asthma-guidelines/ full-report. Accessed Oct 122016.

8. Bell MC, Busse WW. The Biology of Asthma. In: Grippi MA, Elias JA, Fishman JA, Kotloff RM, Pack AI, Senior RM, Siegel MD, editors. Fishman's pulmonary diseases and disorders [Internet]. 5th ed. NYC: McGraw-Hill Education; 2015. http://access medicine.mhmedical.com.eres.library.manoa.hawaii. edu/content . aspx ?bookid $=1344 \&$ Sectionid $=811887$ 82. Accessed Sep 292016.

9. Johansson AK, Sergejeva S, Sjostrand M, Lee JJ, Lotvall J. Allergen-induced traffic of bone marrow eosinophils, neutrophils and lymphocytes to airways. Eur J Immunol. 2004;34:3135-45.

10. Busse WW, Lemanske RF. Asthma. N Engl J Med. 2001;344(5):350-62.

11. Stevenson DD, Szczeklik A. Clinical and pathologic perspectives on aspirin sensitivity and asthma. J Allergy Clin Immunol. 2006;118(4):773-86 (quiz 787-8, Epub 2006 Sep 1).

12. Holgate ST, Polosa R. The mechanisms, diagnosis, and management of severe asthma in adults. Lancet. 2006;368(9537):780-93.

13. Lemanski RF. Issues in understanding pediatric asthma: epidemiology and genetics. J Allergy Clin Immunol. 2002;109(6 Suppl):S521-4.

14. Barnes PJ. Review inhaled corticosteroids. Pharmaceuticals (Basel). 2010;3(3):514-40.

15. Dostert A, Heinzel T. Negative glucocorticoid receptor response elements and their role in glucocorticoid action. Curr Pharm Des. 2004;10:2807-16.
16. Mak JCW, Nishikawa M, Barnes PJ. Glucocorticoids increase $\beta 2$-adrenergic receptor transcription in human lung. Am J Physiol. 1995;12:L41-6.

17. Baraniuk JN, Ali M, Brody D, et al. Glucocorticoids induce $\beta 2$-adrenergic receptor function in human nasal mucosa. Am J Respir Crit Care Med. 1997;155:704-10.

18. Ito J, Ito $\mathrm{M}$, Elliott $\mathrm{WM}$, et al. Decreased histone deacetylase activity in chronic obstructive pulmonary disease. New Engl J Med. 2005;352: 1967-76.

19. Hew M, Bhavsar P, Torrego A, et al. Relative corticosteroid insensitivity of peripheral blood mononuclear cells in severe asthma. Am J Respir Crit Care Med. 2006;174:134-41.

20. Barnes PJ. Role of HDAC2 in the pathophysiology of COPD. Ann Rev Physiol. 2009;71:451-64.

21. Derendorf H. Pharmacokinetic and pharmacodynamics properties of inhaled ciclesonide. J Clin Pharmacol. 2007;47(6):782-9.

22. Derendorf H, Nave R, Drollmann A, Cerasoli F, Wurst W. Relevance of pharmacokinetics and pharmacodynamics of inhaled corticosteroids to asthma. Eur Respir J. 2006;28(5):1042-50.

23. Hubner M, Hochhaus G, Derendorf H. Comparative pharmacology, bioavailability, pharmacokinetics, and pharmacodynamics of inhaled glucocorticosteroids. Immunol Allergy Clin $\mathrm{N}$ Am. $2005 ; 25(3): 469-88$.

24. Kelly HW. Pharmaceutical characteristics that influence the clinical efficacy of inhaled corticosteroids. Ann Allergy Asthma Immunol. 2003;91: 326-34.

25. Sobande PO, Kercsmar CM. Inhaled corticosteroids in asthma management. Respir Care. 2008;53(5):625-33.

26. Daley-Yates PT. Inhaled corticosteroids: potency, dose equivalence and therapeutic index. Br J Clin Pharmacol. 2015;80(3):372-80.

27. Kelly HW. Comparison of inhaled corticosteroids: an update. Annu Pharmacother. 2009;43(3):519-27.

28. Deeks ED, Perry CM. Ciclesonide: a review of its use in the management of asthma. Drugs. 2008;68: 1741-70.

29. Sharpe M, Jarvis B. Inhaled mometasone furoate: a review of its use in adults and adolescents with persistent asthma. Drugs. 2001;61:1325-50. 
30. Edsbacker S, Brattsand R. Budesonide fatty-acid esterification: a novel mechanism prolonging binding to airway tissue. Review of available data. Ann Allergy Asthma Immunol. 2002;88:609-16.

31. Miller-Larsson A, Mattsson H, Hjertberg E, Dahlback M, Tunek A, Brattsand R. Reversible fatty acid conjugation of budesonide. Novel mechanism for prolonged retention of topically applied steroid in airway tissue. Drug Metab Dispos. 1998;26:623-30.

32. Nave R, Meyer W, Fuhst R, Zech K. Formation of fatty acid conjugates of ciclesonide active metabolite in the rat lung after 4-week inhalation of ciclesonide. Pulm Pharmacol Ther. 2005;18:390-6.

33. Mukker JK, Singh RSP, Derendorf H. Ciclesonide: a pro-soft drug approach for mitigation of side effects of inhaled corticosteroids. J Pharm Sci. 2016;105:2509-14.

34. Szefler SJ, Martin RJ, King TS, et al. Significant variability in response to inhaled corticosteroids for persistent asthma. J Allergy Clin Immunol. 2002;109(3):410-8.

35. Wells KE, Peterson EL, Ahmedani BK, Williams LK. Real world effects of once vs. greater daily inhaled corticosteroid dosing on medication adherence. Ann Allergy Asthma Immunol. 2013;111(3):216-20.

36. Williams LK, Peterson EL, Wells K, et al. Quantifying the proportion of severe asthma exacerbations attributable to inhaled corticosteroid nonadherence. J Allergy Clin Immunol. 2011;128(6):1185-91.

37. Chauhan BF, Chartrand C, Ducharme FM. Intermittent versus daily inhaled corticosteroids for persistent asthma in children and adults. Cochrane Database Syst Rev. 2012:CD009611. doi:10.1002/ 14651858CD009611.pub2.

38. Dolovich MA, MacIntyre NR, Dhand R, Gross NJ, Hess, Pierson DJ. Consensus conference on aerosols and delivery devices. Respir Care. 2000;45:588-776.

39. Dekhuijzen PNR, Lavorini F, Usmani OS. Patients' perspectives and preferences in the choice of inhalers: the case for Respimat ${ }^{\circledR}$ or HandiHaler ${ }^{\circledR}$. Dovepress. 2016;10:1561-72.

40. Anderson P. Use of Respimat Soft Mist inhaler in COPD patients. Int J Chron Obstruct Pulmon Dis. 2006;1(3):251-9.

41. Lavorini F, Fontana GA, Usmani OS. New inhaler devices-the good, the bad and the ugly. Respiration. $2014 ; 88(1): 3-15$.

42. Bousquet J, Ben-Joseph R, Messonnier M, Alemao E, Gould AL. A meta-analysis of the dose-response relationship of inhaled corticosteroids in adolescents and adults with mild to moderate persistent asthma. Clin Ther. 2002;24:1-20.

43. Dahl R, Lundback B, Malo JL, International Study Group, et al. A dose-ranging study of fluticasone propionate in adult patients with moderate asthma. Chest. 1993;104:1352-8.

44. Gaddie J, Reid IW, Skinner C, Petrie GR, Sinclair DJ, Palmer KN. Aerosol beclomethasone dipropionate: a dose-response study in chronic bronchial asthma. Lancet. 1973;ii:280-1.

45. Welch M, Bernstein D, Gross G, Kane RE, Banerji D, Azmacort HFA Study Group. A controlled trial of chlorofluorocarbon-free triamcinolone acetonide inhalation aerosol in the treatment of adult patients with persistent asthma. Chest. 1999;116:1304-12.

46. Kemp JP, Berkowitz RB, Miller SD, Murray JJ, Nolop $\mathrm{K}$, Harrison JE. Mometasone furoate administered once daily is as effective as twice-daily administration for treatment of mild-to-moderate persistent asthma. J Allergy Clin Immunol. 2000;106:485-92.

47. Busse WW, Chervinsky P, Condemi J, et al. Budesonide delivered by Turbuhaler is effective in a dose-dependent fashion when used in the treatment of adult patients with chronic asthma. J Allergy Clin Immunol. 1998;101(4 Pt 1):457-63.

48. Currie GP, Fowler SJ, Lipworth BJ. Dose response of inhaled corticosteroids on bronchial hyperresponsiveness: a meta-analysis. Ann Allergy Asthma Immunol. 2003;90:194-8.

49. Gibson PG, Saltos N, Borgas T. Airway mast cells and eosinophils correlate with clinical severity and airway hyperresponsiveness in corticosteroid-treated asthma. J Allergy Clin Immunol. 2000;105:752-9.

50. Jatakanon A, Lim S, Chung KF, Barnes PJ. An inhaled steroid improves markers of airway inflammation in patients with mild asthma. Eur Respir J. 1998;12:1084-8.

51. Hojo M, Kudo K. Dose-response relationship for inhaled corticosteroids and the add-on effect of long-acting $\beta_{2}$-adrenergic receptor agonists in adult chronic asthmatics. Allergol Int. 2004;43:291-9.

52. Pedersen S, O'Byrne P. A comparison of the efficacy and safety of inhaled corticosteroids in asthma. Allergy. 1997;52(Suppl):1-34.

53. Kelly HW. Potential adverse effects of the inhaled corticosteroids. J Allergy Clin Immunol. 2003;112:469-78.

54. Pauwels RA, Lofdahl CG, Postma DS, Formoterol and Corticosteroids Establishing Therapy (FACET) 
International Study Group et al. Effect of inhaled formoterol and budesonide on exacerbations of asthma. N Engl J Med. 1997;337-1405-11.

55. Rank MA, Peters SP. The risks, benefits, and uncertainties of stepping down asthma medications. J Allergy Clin Immunol Pract. 2014;2(5):503-9.

56. Global Initiative for Asthma (GINA). Pocket guide for asthma management and prevention (for adults and children older than 5 years). Updated 2017. http://ginasthma.org/2017-pocket-guide-for-asthmamanagement-and-prevention/. Accessed April 4 2017.

57. Martinez FD, Chinchilli VM, Morgan WJ, et al. Use of beclomethasone dipropionate as rescue treatment for children with mild persistent asthma (TREXA): a randomized, double-blind, placebo-controlled trial. Lancet. 2011;377:650-7.

58. Juniper EF, Kline PA, Vanzieleghem MA, Hargreave FE. Reduction of budesonide after a year of increased use: a randomized controlled trial to evaluate whether improvements in airway responsiveness and clinical asthma are maintained. J Allergy Clin Immunol. 1991;87:483-9.

59. ZuWallack RL, Rosen JP, Cohen L, et al. The effectiveness of once-daily dosing of inhaled flunisolide in maintaining asthma control. J Allergy Clin Immunol. 1997;99:278-85.

60. Visser ML, Postma DS, Arends LR, de Vries TW, Duiverman EJ, Brand PL. One-year treatment with different dosing schedules of fluticasone propionate in childhood asthma. Am J Respir Crit Care Med. 2001;164:2073-7.

61. Hawkins G, McMahon AD, Twaddle S, Wood SF, Ford I, Thomson NC. Stepping down inhaled corticosteroids in asthma: a randomized controlled trial. BMJ. 2003;326:1115.

62. Papi A, Canonica GW, Maestrelli P, et al. Rescue use of beclomethasone and albuterol in a single inhaler for mild asthma. N Engl J Med. 2007;356:2040-52.

63. American Lung Association Asthma Clinical Research Network. Randomized comparison of strategies for reducing treatment in mild persistent asthma. N Engl J Med. 2007;356:2027-39.

64. Tonelli M, Bacci E, Dente FL, et al. Predictors of symptom recurrence after lose-dose inhaled corticosteroid cessation in mild persistent asthma. Respir Med. 2006;100:622-9.

65. Leuppi JD, Salome CM, Jenkins CR, Anderson SD, Xuan W, Marks GB, Koskela H, Brannan JD, Freed R, Andersson M, Chan HK, Woolcock AJ. Predictive markers of asthma exacerbation during stepwise dose reduction of inhaled corticosteroids. Am J Respir Crit Care Med. 2001;163:406-12.

66. Belda J, Parameswaran K, Lemiere C, Kamada D, O'Byrne PM, Hargreave FE. Predictors of loss of asthma control induced by corticosteroid withdrawal. Can Resp J. 2006;13:129-33.

67. Tsurikisawa N, Oshikata C, Tsuburai T, et al. Markers for step-down of inhaled corticosteroid therapy in adult asthmatics. Allergol Int. 2012;61:419-29.

68. Rank MA, Branda ME, McWilliams DB, et al. Outcomes of stepping down asthma medications in a guideline-based pediatric asthma management program. Ann Allergy Asthma Immunol. 2013;110:354-8.

69. Zacharasiewicz A, Wilson N, Lex C, et al. Clinical use of noninvasive measurements of airway inflammation in steroid reduction in children. Am J Respir Crit Care Med. 2005;171:1077-82.

70. Hoffmann HJ, Nielsen LP, Harving H, Heinig JH, Dahl R. Asthmatics able to step down from inhaled corticosteroid treatment without loss of asthma control have low serum eotaxin/CCL11. Clin Respir J. 2008;2:149-57.

71. Baba K, Sakakibara A, Yagi T, Niwa S, Wakayama H, Takagi K. Long-term observations of the clinical course after step down of corticosteroid inhalation therapy in adult chronic asthmatics: correlation with serum levels of eosinophil cationic protein. Respirology. 2002;7:255-66.

72. Jatakanon A, Lim S, Kharitonov SA, Chung KF, Barnes PJ. Correlation between exhaled nitric oxide, sputum eosinophils, and methacholine responsiveness in patients with mild asthma. Thorax. 1998;53:91-5.

73. Berlyne GS, Parameswaran K, Kamada D, Efthimiadis A, Hargreave FE. A comparison of exhaled nitric oxide and induced sputum as markers of airway inflammation. J Allergy Clin Immunol. 2000;106:638-44.

74. Mehta V, Stokes JR, Berro A, Romero FA, Casale TB. Time-dependent effects of inhaled corticosteroids on lung function, bronchial hyperresponsiveness, and airway inflammation in asthma. Ann Allergy Asthma Immunol. 2009;103:31-7.

75. Smith AD, Cowan JO, Brassett KP, Herbison GP, Taylor DR. Use of exhaled nitric oxide measurements to guide treatment in chronic asthma. $\mathrm{N}$ Engl J Med. 2005;352:2163-73.

76. Greening AP, Ind PW, Northfield M, Shaw G, Allen \& Hanburys Limited UK Study Group. Added salmeterol versus higher-dose corticosteroid in asthma 
patients with symptoms on existing inhaled corticosteroid. Lancet. 1994;344:219-24.

77. Shrewsbury S, Pyke S, Britton M. Meta-analysis of increased dose of inhaled steroid or addition of salmeterol in symptomatic asthma (MIASMA). BMJ. 2000;320:1368-73.

78. Peters SP, Bleecker ER, Canonica GW, et al. Serious asthma events with budesonide plus formoterol vs. budesonide alone. $\mathrm{N}$ Engl J Med. 2016;375(9):850-60.

79. Stempel DA, Raphiou IH, Kral KM, et al. Serious asthma events with fluticasone plus salmeterol versus fluticasone alone. $\mathrm{N}$ Engl $\mathrm{J}$ Med. 2016;374(19):1822-30.

80. Castle W, Fuller R, Hall J, Palmer J. Serevent Nationwide Surveillance Study: comparison of salmeterol with salbutamol in asthmatic patients who require regular bronchodilator treatment. BMJ. 1993;306:1034-7.

81. Nelson HS, Weiss ST, Bleecker ER, Yancey SW, Dorinsky PM. The Salmeterol Multicenter Asthma Research Trial: a comparison of usual pharmacotherapy for asthma or usual pharmacotherapy plus salmeterol. Chest. 2006;129:15-26.

82. Bateman ED, Boushey HA, Bousquet J, Busse WW, Clark $\mathrm{TJH}$, et al. Can guideline-defined asthma control be achieved? The gaining optimal asthma control study. Am J Respir Crit Care Med. 2004;170:836-44.

83. O'Byrne PM, Barnes PJ, Rodriguez-Roisin R, et al. Low dose inhaled budesonide and formoterol in mild persistent asthma: the OPTIMA randomized trial. Am J Respir Crit Care Med. 2001;164(8 Pt 1):1392-7.

84. O'Byrne PM, Bisgaard H, Godard PP, et al. Budesonide/formoterol combination therapy as both maintenance and reliever medication in asthma. Am J Respir Crit Care Med. 2005;171:129-36.

85. Rabe KF, Pizzichini E, Stallberg B, et al. Budesonide/formoterol in a single inhaler for maintenance and relief in mild-to-moderate asthma: a randomized, double-blind trial. Chest. 2006;129:246-56.

86. Scicchitano R, Aalbers R, Ukena D, et al. Efficacy and safety of budesonide/formoterol single inhaler therapy versus a higher dose of budesonide in moderate to severe asthma. Curr Med Res Opin. 2004;20:1403-18.

87. Lambrecht BN, Hammad H. The immunology of asthma. Nat Immunol. 2015;16:45-56.

88. US Food and Drug Administration. FDA drug safety communication: new safety requirements for long-acting inhaled asthma medications called long-acting beta-agonists (LABAs); 2010. http:// www.fda.gov/Drugs/DrugSafety/PostmarketDrug SafetyInformationforPatientsandProviders/ucm 200 776.htm. Accessed on April 42017.

89. Mori K, Fujisawa T, Inui N, et al. Step-down treatment from medium-dosage of budesonide/formoterol in controlled asthma. Respir Med. 2016;119:1-6.

90. Bozek JL, Kraft M, Krishnan JA, et al. Long-acting beta-agonist step-off in patients with controlled asthma. Arch Intern Med. 2012;172(18):1365-75.

91. Allen DB, Leonard B, Hartmut D, Robert D, Gene LC, Szefler SJ. Inhaled corticosteroids: past lessons and future issues. J Allergy Clin Immunol. 2003;112(3 Suppl):S1-40.

92. Brutsche $\mathrm{MH}$, Brutsche IC, Munawar $\mathrm{M}$, et al. Comparison of pharmacokinetics and systemic effects of inhaled fluticasone propionate in patients with asthma and healthy volunteers: a randomized crossover study. Lancet. 2000;356:556-61.

93. Weiner P, Berar-Yanay N, Davidovich A, Magadle R. Nocturnal cortisol secretion in asthmatic patients after inhalation of fluticasone propionate. Chest. 1999;116:931-4.

94. Pedersen S, O'Byrne P. A comparison of the efficacy and safety of inhaled corticosteroids in asthma. Allergy. 1997;52(Suppl 39):1-34.

95. Salvatoni A, Piantanida E, Nosetti L, Nespoli L. Inhaled corticosteroids in childhood asthma: long-term effects on growth and adrenocortical function. Paediatr Drugs. 2003;5:351-61.

96. Meibohm B, Hochhaus G, Rohatagi S, et al. Dependency of cortisol suppression on the administration time of inhaled corticosteroids [published correction appears in J Clin Pharmacol. 1997;37:1000]. J Clin Pharmacol. 1997;37:704-10.

97. Barnes NC. Safety of high-dose inhaled corticosteroids. Respir Med. 1993;87(Suppl A):27-31.

98. Todd GR, Acerini CL, Ross-Russell R, Zahra S, Warner JT, McCance D. Survey of adrenal crisis associated with inhaled corticosteroids in the UK. Arch Dis Child. 2002;87:457-61.

99. Martin RJ, Szefler SJ, Chinchilli VM, et al. Systemic effect comparisons of six inhaled corticosteroid preparations. Am J Respir Crit Care Med. 2002;165(10):1377-83.

100. Lipworth BJ. Systemic adverse effects of inhaled corticosteroid therapy: a systemic review and meta-analysis. Arch Intern Med. 1999;159:941-55. 
101. Wolthers OB, Hansen M, Juul A, Nielsen NK, Pedersen $\mathrm{S}$. Knemometry, urine cortisol excretion, and measures of the insulin-like growth factor axis and collagen turnover in children treated with inhaled glucocorticosteroids. Pediatr Res. 1997;41:44-50.

102. Kannisto S, Korppi M, Remes K, Voutilainen R. Adrenal suppression, evaluated by a low dose adrenocorticotropin test, and growth in asthmatic children treated with inhaled steroids. J Clin Endocrinol Metab. 2000;85:652-7.

103. Barnes NC, Hallett C, Harris TA. Clinical experience with fluticasone propionate in asthma: a meta-analysis of efficacy and systemic activity compared with budesonide and beclomethasone dipropionate at half the microgram dose or less. Respir Med. 1998;92:95-104.

104. The Childhood Asthma Management Program. (CAMP) Research Group. Long-term effects of budesonide or nedocromil in children with asthma. N Engl J Med. 2000;343:1054-63.

105. Silverstein MD, Yunginger JW, Reed CE, et al. Attained adult height after childhood asthma: effect of glucocorticoid therapy. J Allergy Clin Immunol. 1997;99:466-74.

106. Agertoft L, Pedersen S. Effect of long-term treatment with inhaled budesonide on adult height in children with asthma. N Engl J Med. 2000;343:1064-9.

107. Guilbert TW, Morgan WJ, Krawiec M, et al. The Prevention of Early Asthma in Kids study: design, rationale and methods for the Childhood Asthma Research and Education Network. Control Clin Trials. 2004;25(3):286-310.

108. Loke YK, Blanco P, Thavarajah M, Wilson AM. Impact of inhaled corticosteroids on growth in children with asthma: systematic review and meta-analysis. PLoS One. 2015;10(7):e0133428. doi:10.1371/journal.pone.0133428.

109. Kelly WH, Sternberg AL, Lescher R, et al. Effect of inhaled glucocorticoids in childhood on adult height. NEJM. 2012;367:904-12.

110. Hopp RJ, Degan JA, Phelan J, Lappe J, Gallagher GC. Cross-sectional study of bone density in asthmatic children. Pediatr Pulmonol. 1995;20:189-92.

111. Gregson RK, Rao R, Murrills AJ, Taylor PA, Warner JO. Effect of inhaled corticosteroids on bone mineral density in childhood asthma: comparison of fluticasone propionate with beclomethasone dipropionate. Osteoporos Int. 1998;8:418-22.

112. Schlienger RG, Jick SS, Meier CR. Inhaled corticosteroids and the risk of fractures in children and adolescents. Pediatrics. 2004;114(2):469-73.
113. Monadi M, Javadian $\mathrm{Y}$, Cheraghi M, Heidari B, Amiri M. Impact of treatment with inhaled corticosteroids on bone mineral density of patients with asthma: related with age. Osteoporos Int. 2015;262:2013-8

114. Richy F, Bousquet J, Ehrlich GE, et al. Inhaled corticosteroids effects on bone in asthmatic and COPD patients: a quantitative systematic review. Osteoporos Int. 2003;14(3):179-90 (Epub).

115. Laatikainen AK, Kroger HP, Tukiainen HO, Honkanen RJ, Saarikoski SV. Bone mineral density in perimenopausal women with asthma: a population-based cross-sectional study. Am J Respir Crit Care Med. 1999;159(4 Pt 1):1179-85.

116. Ip M, Lam K, Yam L, Kung A, Ng M. Decreased bone mineral density in premenopausal asthma patients receiving long-term inhaled steroids. Chest. 1994;105(6):1722-7.

117. Jung JW, Kang HR, Kim JY, Lee SH, Kim SS, Cho SH. Are asthmatic patients prone to bone loss? Ann Allergy Asthma Immunol. 2014;112(5):426-31. doi:10.1016/j.anai.2014.02.013.

118. Wong CA, Walsh LJ, Smith CJP, Wisniewski AF, Lewis SA, Hubbard $\mathrm{R}$, et al. Inhaled corticosteroid use and bone mineral density in patients with asthma. Lancet. 2000;355:1399-403.

119. Matsumoto $H$, Ishihara $K$, Hasegawa $T$, Umeda $B$, Niimi A, Hino M. Effects of inhaled corticosteroid and short courses of oral corticosteroids on bone mineral density in asthmatic patients: a 4-year longitudinal study. Chest. 2001;120(5):1468-73.

120. Wheelock C, St Anna L. Clinical inquiry. Do inhaled steroids reduce bone mineral density and increase fracture risk? J Fam Pract. 2012;61(8):493-508.

121. Tattersfield AE, Town GI, Johnell O, et al. Bone mineral density in subjects with mild asthma randomized to treatment inhaled corticosteroids or non-corticosteroid treatment for two years. Thorax. 2001;56(4):272-8.

122. Jones A, Fay JK, Burr M, Stone M, Hood K, Roberts $\mathrm{G}$. Inhaled corticosteroid effects on bone metabolism in asthma and mild chronic obstructive pulmonary disease. Cochrane Database Syst Rev. 2002;1:CD003537.

123. Welch MJ. Inhaled steroids and severe viral infections. J Asthma. 1994;31:43-50.

124. Bahceciler NN, Nuhoglu Y, Nursoy MA, Kodalli N, Barlan IB, Basaran MM. Inhaled corticosteroid therapy is safe in tuberculin-positive asthmatic children. Pediatr Infect Dis J. 2000;19:215-8. 
125. Singh S, Amin AV, Loke YK. Long-term use of inhaled corticosteroids and the risk of pneumonia in chronic obstructive pulmonary disease: a meta-analysis. Arch Intern Med. 2009;169:219-29.

126. Singh S, Loke YK. An overview of the benefits and drawbacks of inhaled corticosteroids in chronic obstructive pulmonary disease. Int $\mathrm{J}$ Chron Obstruct Pulmon Dis. 2010;5:189-95.

127. Suissa S, Patenaude V, Lapi F, Ernst P. Inhaled corticosteroids in COPD and the risk of serious pneumonia. Thorax. 2013;68:1029-36.

128. Eurich DT, Lee C, Marrie TJ, Majumdar SR. Inhaled corticosteroids and risk of recurrent pneumonia: a population-based, nested case-control study. Clin Infect Dis. 2013;57:1138-44.

129. McKeever T, Harrison TW, Hubbard R, Shaw D. Inhaled corticosteroids and the risk of pneumonia in people with asthma: a case-control study. Chest. 2013;144:1788-94.

130. Weatherall M, James K, Clay J, et al. Dose-response relationship for risk of non-vertebral fracture with inhaled corticosteroids. Clin Exp Allergy. 2008;38:1451-8.

131. Garbe E, LeLorier J, Boivin JF, Suissa S. Inhaled and nasal glucocorticoids and the risk of ocular hypertension or open-angle glaucoma. JAMA. 1997;277:722-7.

132. Samily N, Walton DS, Dreyer EB. Inhaled steroids: effect on intraocular pressure in patients without glaucoma. Can J Ophthalmol. 1996;31(3):120-3.

133. Pelkonen A, Kari O, Selroos O, Nikander K, Haahtela $\mathrm{T}$, Turpeinen M. Ophthalmologic findings in children with asthma receiving inhaled budesonide. J Allergy Clin Immunol. 2008;122(4):832-4.

134. Capewell S, Reynolds S, Shuttleworth D, Edwards C, Finlay AY. Purpura and dermal thinning associated with high dose inhaled corticosteroids. BMJ. 1990;300:1548-51.

135. Mak VHF, Melchor R, Spiro SG. Easy bruising as a side-effect of inhaled corticosteroids. Eur Resp J. 1992;5:1066-74.

136. Roy A, Leblanc C, Paquette L, Ghezzo H, Cote J, Cartier A, et al. Skin bruising in asthmatic subjects treated with high doses of inhaled steroids: frequency an association with adrenal function. Eur Respir J. 1996;9:226-31.

137. Autio P, Karjalainen J, Risteli L, Kiistala U, Oikarinen A. Effects of an inhaled steroid (budesonide) on skin collagen synthesis of asthma patients in vivo. Am J Respir Crit Care Med. 1996;153:1172-5.
138. Pauwels RA, Lofdahl CG, Laitinen LA, et al. Long-term treatment with inhaled budesonide in persons with mild chronic obstructive pulmonary disease who continue smoking. European Respiratory Society Study on Chronic Obstructive Pulmonary Disease. N Engl J Med. 1999;340:1948-53.

139. Tashkin DP, Murray HE, Skeans M, Murray RP. Skin manifestations of inhaled corticosteroids in COPD patients: results from Lung Health Study II. Chest. 2004;126:1123-33.

140. Daley-Yates PT. Pharmacological aspects of glucocorticoid therapy. In: Wolthers OD, editor. Exogenous glucocorticoids in paediatric asthma. Kerala: Transworld Research Network; 2007. p. 1-18.

141. Daley-Yates PT, Harker AJ, Taylor S, Daniel MJ. Plasma protein binding of inhaled corticosteroids: reappraisal of its significance in systemic pharmacological activity. J Allergy Clin Immunol. 2005;115:S4.

142. Wolthers OD, Daley-Yates PT. Exogenous glucocorticoids in Paediatric asthma. In: Wolthers OD, editor. Inhaled glucocorticoids and hypothalamic-pituitary-adrenal axis function. Kerala: Transworld Research Network; 2007. p. 19-34.

143. Daley-Yates PT, Pierre LN. A physiologically based pharmacokinetic/pharmacodynamic model predicting cortisol suppression for inhaled corticosteroids. Am J Respir Crit Care Med. 2001;163:A518.

144. Crim C, Pierre LN, Daley-Yates PT. A review of the pharmacology and pharmacokinetics of fluticasone propionate and mometosone furoate. Clin Ther. 2001;23:1339-54.

145. Daley-Yates PT, Derks MGM, Weeks AT, Mehta RS, Beerahee M, Sousa A. Pharmacokinetics and pharmacodynamics of fluticasone propionate and mometasone furoate dry powder inhalers in healthy and asthmatic subjects. Am J Respir Crit Care Med. 2005;2:A354.

146. Allen A. The relationship between fluticasone furoate systemic exposure and cortisol suppression. Clin Pharmacokinet. 2013;52:885-96.

147. Hogger P, Rohdewald P. Glucocorticoid receptors and fluticasone propionate. Rev Contemp Pharmacother. 1998;9:501-22.

148. Daley-Yates PT, Kunka RL, Shen YY, Andrews SM, Callejas S, Ng C. Bioavailability of fluticasone propionate and mometasone furoate aqueous nasal sprays. Eur J Clin Pharmacol. 2004;60:265-8.

149. Falcoz C, Oliver R, McDowall J, Ventresca GP, Bye A, Daley-Yates PT. Bioavailability of orally administered micronised fluticasone propionate. Clin Pharmacokinet. 2000;39(Suppl. 1):9-15. 
150. Taylor S, Harker A. Modification of the ultrafiltration technique to overcome solubility and non-specific binding challenges associated with the measurement of plasma protein binding of corticosteroids. J Pharm Biomed Anal. 2006;41:299-303.

151. Derendorf H, Hochhaus G, Meibohm B, Mollmann $\mathrm{H}$, Bart J. Pharmacokinetics and pharmacodynamics of inhaled corticosteroids. J Allergy Clin Immunol. 1998;101:S440-6.

152. Kaliner MA. Pharmacologic characteristics and adrenal suppression with newer inhaled corticosteroids: a comparison of ciclesonide and fluticasone propionate. Clin Ther. 2006;28:319-31.

153. Mager DE, Jusko WJ. Quantitative structure-pharmacokinetic/pharmacodynamic relationships of corticosteroids in man. J Pharm Sci. 2001;91:2442-51.

154. Agertoft L, Pedersen S. Lung deposition and systemic bioavailability of fluticasone Diskus and budesonide Turbuhaler. Am J Respir Crit Care Med. 2003;168:779-82.

155. Mackie AE, McDowall JE, Falcoz C, Ventresca GP, Bye A, Daley-Yates PT. Pharmacokinetics of fluticasone propionate inhaled via the Diskhaler and Diskus powder devices in healthy subjects. Clin Pharmacokinet. 2000;39(1):23-30.

156. Thorsson L, Edsbacker S, Conradson TB. Lung deposition from Turbuhaler is twice that from a pressurised metered dose inhaler P-MDI. Eur Respir J. 1994;7:1839-44.

157. Agertoft L, Andersen A, Weibull E, Pedersen S. Systemic availability and pharmacokinetics of nebulized budesonide in pre-school children with asthma. Arch Dis Child. 1999;80:241-7.

158. Jeal W, Faulds D. Triamcinolone acetonide. A review of its pharmacological properties and therapeutic efficacy in the management of allergic rhinitis. Drugs. 1997;53:257-80.

159. Derendorf H, Hochhaus G, Rohatagi S, Möllmann H, Barth J, Sourgens H, Erdmann M. Pharmacokinetics of triamcinolone acetonide after intravenous, oral, and inhaled administration. J Clin Pharmacol. 1995;35:302-5.

160. Barth J, Damoiseaux M, Möllmann H, Brandis KH, Hochhaus G, Derendorf H. Pharmacokinetics and pharmacodynamics of prednisolone after intravenous and oral administration. Int J Clin Pharmacol Ther Toxicol. 1992;30:317-24.

161. Kelly HW. Comparison of inhaled corticosteroids. Ann Pharmacother. 1998;32:220-32. doi:10.1345/ aph.17014.

162. Winkler J, Hochhaus G, Derendorf H. How the lung handles drugs: pharmacokinetics and pharmacodynamics of inhaled corticosteroids. Proc Am Thorac Soc. 2004; 1:356-63.

163. Hübner M, Hochhaus G, Derendorf H. Comparative pharmacology, bioavailability, pharmacokinetics, and pharmacodynamics of inhaled glucocorticosteroids. Immunol Allergy Clin N Am. 2005;25:469-88.

164. Derendorf H, Nave R, Drollman A, Cerasoli F, Wurst $\mathrm{W}$. Relevance of pharmacokinetics and pharmacodynamics of inhaled corticosteroids to asthma. Eur Respir J. 2006;28:1042-50. 